\title{
A Case of Ectopic Growth Hormone Releasing Hormone (GHRH) from Pancreatic Neuroendocrine Tumor Resistant to Therapy
}

\author{
Ohoud Almohareb $^{1 *}$, Juan Rivera ${ }^{2}$ \\ ${ }^{1}$ Specialized Diabetes and Endocrine Center, King Fahad Medical City, Riyadh, KSA \\ ${ }^{2}$ Division of Endocrinology, McGill University Health Centre, Montreal, Canada \\ Email: *drohoud@yahoo.com
}

Received May 26, 2013; revised June 25, 2013; accepted July 1, 2013

Copyright (C) 2013 Ohoud Almohareb, Juan Rivera. This is an open access article distributed under the Creative Commons Attribution License, which permits unrestricted use, distribution, and reproduction in any medium, provided the original work is properly cited.

\begin{abstract}
Introduction: Ectopic secretion of GHRH is a rare cause of acromegaly. However, its recognition is clinically important because different therapeutic approaches are required. Case Presentation: We present a challenging case of acromegaly secondary to ectopic GHRH secretion from pancreatic neuroendocrine tumor in a 52-year-old female. The patient is treated with different modalities which include pegvisomant in an attempt to control the stimulated GH-axis considering the limited data about its use in treatment of ectopic acromegaly. Conclusion: GHRH-secreting tumor is a rare cause of acromegaly. Surgical resection of the tumor is the therapy of choice whenever possible. However, further studies are warranted for unresectable tumor or resistant cases.
\end{abstract}

Keywords: Ectopic GHRH; Acromegaly; Pancreatic Neuroendocrine Tumor

\section{Case Report}

A 52-year-old woman presented initially in May 2007 with a $2.5 \mathrm{~cm}$ firm non-tender nodule over her right triceps area and significant weight loss over 1 year. Medical history included left breast cancer for which she had undergone mastectomy followed by chemotherapy at age of 34. She had no evidence of disease since then. Excisional biopsy of the right arm lesion and further diagnostic work-up revealed metastatic well differentiated neuroendocrine carcinoma originating from a large $(10 \times 6$ $\mathrm{cm})$ pancreatic tail mass. An octreotide scan was negative. She received 7 cycles of chemotherapy (carboplatin and gemcitabine) followed by palliative radiotherapy for spinal propagation of her retroperitoneal tumor. Several months later, radiological imaging showed stable disease.

On January 2009, she was admitted because of heart failure secondary to cardiomyopathy. Coarse facial features noticed this admission prompted a work-up for acromegaly. This diagnosis was confirmed on the basis of elevated serum insulin-like growth factor 1 (IGF-I) 77 $\mathrm{nmol} / \mathrm{L}$ (reference range, $10-29.4 \mathrm{nmol} / \mathrm{L}$ ) and growth

\footnotetext{
"Corresponding author.
}

hormone (GH) of $14.4 \mathrm{ug} / \mathrm{L}$ (reference range, $0.03-4.00$ $\mathrm{ug} / \mathrm{L}$ ) that failed to be suppressed during oral glucose toler- ance test. A normal sellar MRI prompted the requisition of serum Growth Hormone-Releasing Hormone (GHRH) which was indeed elevated at $185 \mathrm{pg} / \mathrm{ml}$ (reference range, $5-18 \mathrm{pg} / \mathrm{ml}$ ) strongly favoring ectopic acromegaly syndrome. The remaining pituitary function normal included a serum prolactin of $5.6 \mathrm{mcg} / \mathrm{L}$ (reference range, $3.3-26.7 \mathrm{mcg} / \mathrm{L}$ ).

She started on octreotide LAR monthly injections. Everolimus $10 \mathrm{mg}$ daily was added for a short period as she developed a skin reaction that forced to stop it. During this period, she had fine needle aspiration cytology (FNAC) from right firm thyroid nodule that was measured as $1.5 \mathrm{~cm}$ and reported as possible medullary thyroid cancer (MTC). Calcitonin level was $<2 \mathrm{ng} / \mathrm{L}$ (reference range $0-10 \mathrm{ng} / \mathrm{L}$ ). She underwent right hemithyroidectomy and neck dissection. The final pathology was metastatic well differentiated pancreatic neuroendocrine carcinoma rather than MTC. As the tumor was invading the recurrent laryngeal nerve on the opposite side, it was decided that no further surgery would be offered for the neck lesions. Also, she was discovered to 
have left superior parathyroid adenoma which has been resected. Multiple Endocrine Neoplasia (MEN) screening revealed one high parathyroid hormone $(\mathrm{PTH})$ reading of $10.68 \mathrm{pmol} / \mathrm{L}$ (reference range, $1.60-6.90 \mathrm{pmol} / \mathrm{L}$ ) in face of normal serum calcium concentration.

The pancreatic tumor, which had initially been considered unresectable at another center, was reassessed by our surgical team. It was decided that good tumor debulking could be achieved. She underwent elective surgery in August 2010 involving distal pancreatectomy and splenectomy, partial liver resection, cholecystectomy and perinephric tumor excision. Post-surgically IGF-I concentrations fell to around $40-45 \mathrm{nmol} / \mathrm{L}$, which were still about 30\% above the upper limit of normal. Therefore octreotide LAR was resumed. Post-surgical CT imaging showed no residual pancreatic tumor, however progression of liver involvement was reported. Her clinical complaints of hot flushes, diarrhea and spinal cord compression symptoms became significant at this point. Therefore, sunitinib $37.5 \mathrm{mg}$ daily was added to the monthly $60 \mathrm{mg}$ of octreotide. Three months later, the radiological imaging showed massive metastatic lesions in the liver, bone, lungs and new lesion in right breast which were confirmed pathologically to have the same nature of the other tumors foci. Six cycles of chemotherapy (dacarbazine and 5-fluorouracil) also did not halt her disease progression at this point although clinically she seemed better.

In an effort to suppress the IGF-I production, pegvisomant $10 \mathrm{mg}$ daily was added to octreotide for a period of 6 months. Shortly after initiating pegvisomant, her IGF-I had been completely normalized (from 67.1 to $15.2 \mathrm{nmol} / \mathrm{L}$ ). Unfortunately she had a pelvis fracture in October 2012 at the site of a bone metastasis and was admitted to another hospital. The oncology considered that at this point all her treatment was probably futile and in agreement with the patient, all but essential medications were discontinued. She was then transferred to a hospice. At this point we lost further contact with the patient.

\section{Discussion}

Ectopic secretion of Growth Hormone Releasing Hormone (GHRH) accounts for $<1 \%$ of acromegaly cases [1]. However, its early recognition is clinically important because in such cases acromegaly may be a sign of an aggressive tumor, and different therapeutic approaches are required. GHRH-secreting neuroendocrine tumors (NETs) are the commonest cause of ectopic GHRH secretion causing acromegaly with bronchial carcinoids accounting for $54 \%$ of cases followed by pancreatic NETs in $30 \%$ of cases [2].

The clinical features of ectopic GHRH-secreting tumors causing acromegaly are indistinguishable from those caused by GH-secreting pituitary adenomas. However, symptoms due to the underlying neoplasm or cosecretion of other substances by the tumor might be suggestive of an ectopic origin. GHRH-omas in the pancreas are often single, large tumors arising from the tail of pancreas which might explain the late discovery. One third of patients have liver metastases at diagnosis [3]. Pancreatic NETs can occur sporadically or as a part inherited disorders such as multiple endocrine neoplasial (MEN 1), von Hippel-Lindau syndrome (VHL), neurofibromatosis 1 (NF-1), and occasionally in patients with tuberous sclerosis [4]. However, the vast majority of the pancreatic NETs associated with inherited disorders are non-functional. GHRH producing pancreatic neuroendocrine tumors are associated with MEN 1 in $16 \%$ of cases, and more than $60 \%$ are malignant [5].

Regardless of the cause, GH and IGF-I are invariably elevated and GH levels fail to suppress after an oral glucose load in all forms of acromegaly. Dynamic pituitary tests are not helpful in distinguishing pituitary acromegalic patients from those harboring extrapituitary tumors. The diagnosis is usually established by presence of an elevated plasma GH levels accompanied by elevated plasma GHRH levels. Imaging of the sellar region is necessary to verify the presence and size of a pituitary lesion even if the diagnosis of ectopic GHRH secretion has been established. Different radiological tools can be used to localize the GHRH-secreting tumor such as chest CT scan, trans-abdominal or endoscopic ultrasound, abdominal CT scan and MRI. Octreotide scan can provide additional tool as these tumors very often express subtype 2 and 5 of the somatostatin receptors. However, despite the high sensitivity of octreotide scan in diagnosing of NET, tumor differentiation significantly impact the octreotide uptake [6]. Inferior to octreotide scan is metaiodobenzylguanidine (MIBG) which is also useful in functioning midgutenterochromaffin cell metastases [6]. Both radiolabeled octreotide analogs and MIBG represent 2 different approaches for imaging and targeting metastatic gastroeneteropancreatic NET but, both were negative in our patient.

Important clues to the presence of a GHRH producing acromegaly are absence of a pituitary tumor on imaging [2] and clinical and biochemical features of other tumors known to be associated with extra pituitary acromegaly (e.g. respiratory wheezing, facial flushing, peptic ulcers or renal stones). However, the diagnosis of an ectopic production of GHRH can be a challenging task and some cases have undergone unnecessary pituitary resections [7]. Of note, while somatotrophic hyperplasia may be a universal finding in ectopic GHRH syndrome, adenoma [8] or adenoma-like transformation [9] have also been described. In fact, animal studies have demonstrated that chronic GHRH stimulation may induce progression of pituitary somatotrophic hyperplasia to somatotropinoma in mice $[10,11]$. 
Despite the fact that the initial isolation of GHRH was from pancreatic islet cell tumors from patients with ectopic acromegaly [12] and not from the hypothalamus, initially little attention was given to its potential role in tumorigenesis. Two lines of evidence direct the attention to the role of GHRH in tumorigenesis [13]. The first is its expression in many types of non-pituitary tumors. The second is the result of its inhibition by antagonists of GHRH in vitro in cancer cells where the endocrine GHRH/GH/IGF-I axis is not operational. GHRH may also affect cancer development via up regulation of hepatic IGF-I production, and tumoral IGF-I and IGF-II secretion [13]. Earlier studies supported the direct action of GHRH in cancer development where the GHRH antagonists inhibited cell proliferation and tumor growth. However this effect was not always accompanied by GH and IGF-I levels reduction [14-16]. Further studies showed that GHRH regulates the reactive oxygen (ROS) and nitrogen (NOS) species metabolism in prostate cancer cells in vitro while a GHRH antagonist possesses an antioxidative activity [17]. Interestingly, GHRH antagonists effects seem to be more pronounced in tumors known or suspected to be neuroendocrine in nature (e.g. small cell lung carcinoma and prostate) or endocrine dependent (e.g. breast cancer) [18]. Therefore, GHRH antagonists sound promising as a future treatment (biomodulator) in neuroendocrine tumors.

The secretion of both GH and ectopic GHRH has been shown to be pulsatile [19]. However, there is no correlation between changes in plasma GH and GHRH concentrations [19]. The presence of immunoreactive GHRH in many tumors while ectopic acromegaly remains an uncommon occurrence in these patients may suggest that the majority of circulating GHRH immunoreactivity consists of non-biologically active GHRH fragments or disordered tissue processing of GHRH [19,20] with rapid cleavage of GHRH (1-44) to more stable but biologically inactive fragments [21]. Together with the fact that such tumors not only produced GHRH but the GHRH-receptor as well [22] support the hypothesis that GH hypersecretion in ectopic GHRH syndrome requires GHRH receptor occupancy and make the GHRH antagonists attractive tool to study the potential involvement of endogenous GHRH in acromegaly. Szalontay et al. study provides direct evidence for effectiveness of GHRH antagonists on human pituitary GH-secreting adenoma tissue and strongly suggests their usefulness in other forms of acromegaly or for those who failed surgery [23].

Treatment of ectopic acromegaly involves surgical resection of the tumor whenever possible. Long-acting somatostatin analogs are generally successful in the initial management of patients with GHRH-omas. The long acting somatostatin analogs may be able to control the ectopic hormonal secretion and tumor growth. The effi- cacy of somatostatin analogs depends on the pattern of somatostatin receptor (SSTR) expression in the tumor. For this reason there is usually a better response in pituitary adenomas causing acromegaly where the GH secreting pituitary adenomas express mainly SSTR2 and 5, while SSTR1 is expressed mainly in mixed GH-prolactin adenomas [24]. In occasional patients, somatostatin therapy is not adequate and addition of $\alpha$-interferon to the somatostatin analogs may help to control the symptoms [25]. In our patient, the long acting octreotide failed to suppress GH and IGF-I secretion. A negative octreoscan does not preclude the use of octreotide as an anti-proliferative agent in these tumors, because it is well known that octreoscan positivity requires much greater receptor expression than the biological anti-proliferative and antisecretory actions, and also because treatment with octreotide could result in increased expression of SSTR2 in tumor cells.

The standard chemotherapy regimens that target GHRH producing tumors are generally unsuccessful in controlling the activated GH axis [20]. Molecular targeted therapies with tyrosine kinase inhibitors such as sunitinib and inhibitors of mTOR are still under investigation [5]. In an attempt to control the stimulated GHaxis we added pegvisomant to our patient's therapy with octreotide and sunitinib. This GH receptor antagonist is an effective therapy for lowering IGF-I in patients with GH secreting pituitary adenoma. However, data respecting its use in ectopic GHRH causing acromegaly is limited although it might be useful in resistant cases of ectopic GHRH [26-28]. Our patient tolerated pegvisomant extremely well and the biochemical response (normalization of IGF-I) was quickly achieved. Unfortunately, her tumor had already at this point spread widely to the bones, liver and lungs with bone complications leading to a precipitated adverse outcome in her case.

\section{Conclusion}

GHRH secreting tumor is a rare cause of acromegaly. However, its recognition is clinically important because more different therapeutic approaches are needed than GH secreting pituitary adenoma. Surgical resection of the tumor is the therapy of choice whenever possible. Pegvisomant seems promising for resistant cases in an attempt to control the GH-axis. However, further studies are warranted. Finally, the experimental results of GHRH antagonists should provide motivation to continue developing new antagonistic analogs of GHRH and explore their potential benefit in human cancers.

\section{REFERENCES}

[1] E. Verrua, C. L. Ronchi, E. Ferrante, et al., "Acromegaly Secondary to an Incidentally Discovered Growth-Hor- 
mone-Releasing Hormone Secreting Bronchial Carcinoid Tumour Associated to a Pituitary Incidentaloma," Pituitary, Vol. 13, No. 3, 2010, pp. 289-292. http://dx.doi.org/10.1007/s11102-008-0146-y

[2] D. C. Metz and R. T. Jensen, "Gastrointestinal Tumors: Pancreatic Endocrine Tumors," Gastroenterology, Vol. 135, No. 5, 2008, pp. 1469-1492. http://dx.doi.org/10.1053/j.gastro.2008.05.047

[3] M. H. Kulke, L. B. Anthony, D. L. Bushnell, et al., "WellDifferentiated Neuroendocrine Tumors of the Stomach and Pancreas," Pancreas, Vol. 39, No. 6, 2010, pp. 735752. http://dx.doi.org/10.1097/MPA.0b013e3181ebb168

[4] R. T. Jensen, M. J. Berna, D. B. Bingham, et al., "Inherited Pancreatic Endocrine Tumor Syndromes: Advances in Molecular Pathogenesis, Diagnosis, Management and Controversies," Cancer, Vol. 113, Suppl. 7, 2008, pp. 18071843. http://dx.doi.org/10.1002/cncr.23648

[5] F. Ehehalt, H. D. Saeger, C. M. Schmidt, et al., "Neuroendocrine Tumors of the Pancreas," The Oncologist, Vol. 14, No. 5, 2009, pp. 456-467. http://dx.doi.org/10.1634/theoncologist.2008-0259

[6] S. Ezziddin, T. Logvinski, C. Yong-Hing, et al., "Factors Predicting Tracer Uptake in Somatostatin Receptor and MIBG Scintigraphy of Metastatic Gastroenteropancreatic Neuroendocrine Tumors," Journal of Nuclear Medicine, Vol. 47, No. 2, 2006, pp. 223-233.

[7] L. V. Neto, G. F. Taboada, L. L. Corrêa, et al., “Acromegaly Secondary to Growth Hormone-Releasing Hormone Secreted by an Incidentally Discovered Pheochromocytoma," EndoChoice Pathology, Vol. 18, No. 1, 2007, pp. 46-52. http://dx.doi.org/10.1007/s12022-007-0006-8

[8] Y. Shintani, K. Yoshimoto, H. Horie, et al., "Two Different Pituitary Adenomas in a Patient with Multiple Endocrine Neoplasia Type 1 Associated with Growth Hormone-Releasing Hormone-Producing Pancreatic Tumor: Clinical and Genetic Features," Endocrine Journal, Vol. 42, No. 3, 1995, pp. 331-340.

http://dx.doi.org/10.1507/endocrj.42.331

[9] D. Zimmerman, W. F. Young Jr., M. J. Ebersold, et al., "Congenital Gigantism Due to Growth Hormone-Releasing Hormone Excess and Pituitary Hyperplasia with Adenomatous Transformation," JCEM, Vol. 76, No. 1, 1993, pp. 216-222.

[10] S. L. Asa, K. Kovacs, L. Stefaneanu, et al., "Pituitary Adenomas in Mice Transgenic for Growth Hormone-Releasing Hormone," Endocrinology, Vol. 131, No. 5, 1992, pp. 2083-2089. http://dx.doi.org/10.1210/en.131.5.2083

[11] R. V. Lloyd, L. Jin, A. Chang, et al., "Morphologic Effects of hGRH Gene Expression on the Pituitary, Liver, and Pancreas of MT-hGRH Transgenic Mice. An in Situ Hybridization Analysis," American Journal of Pathology, Vol. 141, No. 4, 1992, pp. 895-906.

[12] J. Rivier, J. Spiess, M. Thorner, et al., "Characterization of a Growth Hormone-Releasing Factor from a Human Pancreatic Islet Tumor," Nature, Vol. 300, No. 5889, 1982, pp. 276-278. http://dx.doi.org/10.1038/300276a0

[13] H. Kiaris, M. Koutsilieris, A. Kalofoutis, et al., "Growth Hormone-Releasing Hormone and Extra-Pituitary Tumorigenesis: Therapeutic and Diagnostic Applications of
Growth Hormone-Releasing Hormone Antagonists," Expert Opinion on Investigational Drugs, Vol. 12, No. 8, 2003, pp. 1385-1394. http://dx.doi.org/10.1517/13543784.12.8.1385

[14] A. Plonowski, A. V. Schally, M. Letsch, et al., "Inhibition of Proliferation of PC-3 Human Prostate Cancer by Antagonists of Growth Hormone-Releasing Hormone: Lack of Correlation with the Levels of Serum IGF-I and Expression of Tumoral IGF-II and Vascular Endothelial Growth Factor," Prostate, Vol. 52, No. 3, 2002, pp. 173 182. http://dx.doi.org/10.1002/pros.10105

[15] A. Plonowski, J. L. Vagra, A. V. Schally, et al., "Inhibition of PC-3 Human Prostate Cancers by Analogs of Growth Hormone-Releasing Hormone (GH-RH) Endowed with Vasoactive Intestinal Peptide (VIP) Antagonistic Activity," International Journal of Cancer, Vol. 98, No. 4, 2002, pp. 624-629. http://dx.doi.org/10.1002/ijc.10221

[16] I. Chatzistamoul, A. V. Schally, J. L. Vagra, et al., "Inhibition of Growth and Metastases of MDA-MB-435 Human Estrogen-Independent Breast Cancers by an Antagonist of Growth Hormone-Releasing Hormone," Anticancer Drugs, Vol. 12, No. 9, 2001, pp. 761-768. http://dx.doi.org/10.1097/00001813-200110000-00008

[17] N. Barabutis and A. V. Schally, "Growth Hormone-Releasing Hormone: Extrapituitary Effects in Physiology and Pathology," Cell Cycle, Vol. 9, No. 20, 2010, pp. 4110-4116. http://dx.doi.org/10.4161/cc.9.20.13787

[18] M. Doga, S. Bonadonna, A. Burattin, et al., "Ectopic Secretion of Growth Hormone-Releasing Hormone (GHRH) in Neuroendocrine Tumors: Relevant Clinical Aspects," Annals of Oncology, Vol. 12, Suppl. 2, 2001, pp. S89S94. http://dx.doi.org/10.1093/annonc/12.suppl_2.S89

[19] C. Jaffe, R. DeMott-Friberg, L. Frohman, et al., "Suppression of Growth Hormone Hypersecretion Due to Ectopic GHRH by Selective GHRH Antagonist," JCEM, Vol. 82, No. 2, 1997, pp. 634-637.

[20] M. Gola, M. Doga, S. Bonadonna, et al., "Neuroendocrine Tumors Secreting Growth Hormone-Releasing Hormone," Pituitary, Vol. 9, No. 3, 2006, pp. 221-229. http://dx.doi.org/10.1007/s11102-006-0267-0

[21] L. A. Frohman, T. R. Downs, T. C. Williams, et al., "Rapid Enzymatic Degradation of Growth Hormone-Releasing Hormone by Plasma in Vitro and in Vivo to a Biologically Inactive Product Cleaved at the NH2 Terminus," Journal of Clinical Investigation, Vol. 78, No. 4, 1986, pp. 906-913. http://dx.doi.org/10.1172/JCI112679

[22] N. H. Othman, S. Ezzat, K. Kovacs, et al., "Growth Hormone-Releasing Hormone (GHRH) and GHRH Receptor (GHRH-R) Isoform Expression in Ectopic Acromegaly," Clinical Endocrinology, Vol. 55, No. 1, 2001, pp. 135140.

[23] L. Szalontay, R. J. Benveniste, A. V. Schally, et al., "Inhibitory Effects of GHRH Antagonists on Human GHSecreting Adenoma Tissue," Neuroendocrinology, Vol. 96, No. 1, 2012, pp. 81-88. http://dx.doi.org/10.1159/000335989

[24] M. C. Zatelli, D. Piccin, F. Tagliati, et al., "Somatostatin Receptor Subtype 1 Selective Activation in Human Growth Hormone (GH) and Prolactin (PRL) Secreting Pituitary 
Adenomas: Effects on Cell Variability, GH, and PRL Secretion," JCEM, Vol. 88, No. 6, 2003, pp. 2797-2802.

[25] G. Sassolas and J. A. Chayvialle, "GRFomas, Somatostatinomas: Clinical Presentation, Diagnosis and Advances in Management," In: M. Mignon and R. T. Jensen, Eds., Endocrine Tumors of the Pancreas: Recent Advances in Research and Management, Vol. 23, Basel, Karger, 1995, pp. 194-207.

[26] D. E. Weiss, H. Vogel, M. B. S. Lopes, et al., "Ectopic Acromegaly Due to a Pancreatic Neuroendocrine Tumor Producing Growth Hormone Releasing Hormone," En- docrine Practice, Vol. 17, No. 1, 2011, pp. 79-84.

[27] A. Agha, L. Farrell, P. Downey, et al., "Acromegaly Secondary to Growth Hormone Releasing Hormone Secretion," Irish Journal of Medical Science, Vol. 173, No. 4, 2004, pp. 215-216. http://dx.doi.org/10.1007/BF02914554

[28] L. Garby, P. Caron, F. Claustrat, et al., "Clinical Characteristics and Outcome of Acromegaly Induced by Ectopic Secretion of Growth Hormone-Releasing Hormone (GHRH): A French Nationwide Series of 21 Cases," JCEM, Vol. 97, No. 6, 2012, pp. 2093-2104. 